\title{
Using regression analysis method to model and optimize the quality of chip-removing processed metal surfaces
}

\author{
Mihail Aurel Țîțu, ${ }^{1, *}$, and Alina Bianca Pop ${ }^{2}$ \\ ${ }^{1}$ Lucian Blaga University of Sibiu, Victoriei Street no. 10, code 550024, Sibiu, România \\ ${ }^{2}$ SC TechnoCAD SA, Vasile Alecsandri no. 72, code 430351, Baia Mare, România
}

\begin{abstract}
The paper aim is to identify based on regression analysis, the quantitative relationship between the cutting process parameters (cutting speed, cutting depth and feed per tooth) and the arithmetic mean deviation of the surface profile, measured longitudinally and transversely on the cutting feed direction, which describe the system at any point in the chosen experimentally studied range. The equations coefficients means the influence of the variables on the pursued answer.
\end{abstract}

\section{Introduction}

Among the previous research are the investigation of the effect of the feed rate on the surface roughness and the reduction of processing time [1], and also the mathematical modeling of a regression equation of the surface roughness obtained by end milling [2]. This paper is a continuation of the researches conducted in [2].

In the scientific literature, there are studies based on the mathematical modeling such: [3] and [4], in which the implementation of the Taguchi method was analyzed in order to improve the product quality; [5] which used the Response Surface Methodology (RSM) as optimization technique, [6] used the regression analysis and [7] which used ANOVA and the regression analysis. The regression analysis allows to use the experimental data to calculate the equation coefficients that are describing the studied system at any point in the experimentally range.

\section{Research method}

Any experimenter begins an experimental study based on a specific working plan, which will use an experimental plan or some experimental project. The experimenter can reach the desired solution, based on his knowledge in the field, or based on his intuition - but this is rarely achievable. Doing so, it may lose time and money, up to reach an appropriate result, or it may not ever reach the desired objective. Therefore it is necessary to use mathematical statistics methods and optimization methods for a rational choice of the experimental measurements to be carried out and to get reliable and consistent information [4]. In the

*Corresponding author: mihail.titu@ulbsibiu.ro 
first phase to conduct the research it is necessary to establish the process input factors: cutting speed, cutting depth and feed per tooth. Given that the full factorial experiment was used, the number of factors corresponding levels are shown in table 1. Based on these values it is necessary to conduct a number of $6 \times 5 \times 5=150$ experiments. Thus, the 150 cutting regimes obtained under the combinations, were tested by processing of $21 \mathrm{Al} 7136$ blocks with the following dimensions: $500 \times 101 \times 24.5 \mathrm{~mm}$. All of the three parameters takes variables values according to the tool manufacturer recommendation for aluminum machining [8]. The experiment will be performed using a standard tools set of aluminum machining - $16 \mathrm{~mm}$ End milling cutter - SECO R217.69-1616.0-09-2AN, holding two indexable cutting inserts XOEX090308FR-E05, H15. The machine used for the milling tests is a HAAS VF2 CNC. Abundant amounts of Blasocut BC 35 Kombi SW mineral coolant were provided at the cutting zone throughout the experiment. To analyze the surface roughness for different machining conditions it was used the portable surface roughness tester - Mitutoyo SURFTEST SJ-210. The machined surface roughness $R_{a}$ will be measured longitudinally ( $\mathrm{R}_{\mathrm{a}}$ long) and transversely $\left(\mathrm{R}_{\mathrm{a}}\right.$ transv) on the cutting feed direction. Then, the regression equations will be obtained using the least squares method, because the experiment aim is to determine the most accurate constants values for any equation type, assigning equal or unequal weights (as needed), to various experimental data. After the regression equations obtaining, it is necessary to assess the associated experimental data, based on the variance analysis ANOVA. To use the ANOVA test to evaluate the quality match, it is necessary to repeat at least once the experiment in the center of the experimental range. In this research, all the experiments were repeated for seven times. It is very important to know the precision which the coefficient values were predicted, not only their absolute value. Finally, based on the proposed regression model, the arithmetic mean deviation of the surface profile will be determined, and it will be compared with the experimental results.

Table 1. Cutting regime

\begin{tabular}{|c|c|}
\hline \multirow{6}{*}{ Cutting regime } & Cutting speed $[\mathrm{m} / \mathrm{min}]-6$ levels \\
\hline & $\begin{array}{llllll}495 & 530 & 570 & 610 & 660 & 710 \\
\end{array}$ \\
\hline & Cutting depth $[\mathrm{mm}]-5$ levels \\
\hline & $\begin{array}{lllll}2 & 2.5 & 3 & 3.5 & 4\end{array}$ \\
\hline & Feed per tooth $[\mathrm{mm} /$ tooth $]-5$ levels \\
\hline & \begin{tabular}{lllll|}
0.04 & 0.06 & 0.08 & 0.11 & 0.14
\end{tabular} \\
\hline
\end{tabular}

\section{Regression analysis}

\section{1 $R_{\mathrm{a}}$ longitudinal regression analysis}

The entire analysis starts with the studied research factors and the interactions among them, and also the $\mathrm{R}_{\mathrm{a}}$ long and $\mathrm{R}_{\mathrm{a}}$ transv measurements (each with 1050 measurements). From all experimental data tested, the values affected by aberrant error were removed and the rest of data were used further to determinate the regression equations. To facilitate the necessary calculations to achieve the objective, the statistical application MINITAB 17 was used. In this application the experimental data were introduced and by its predefined calculation method, it was determined the squares sum and the percentage distribution for each factor, respectively factors interaction. The freedom degrees were calculated for each factor/interaction, using Taguchi's method. For Ra long situation it was found that the cutting depth B influence is $0.02 \%$ - a negligible value of. It is the same case for interaction between $\mathrm{B}$ and $\mathrm{C}$ factors, whose influence is felt in $0.14 \%$-a small percentage. Therefore, to obtain the regression equation the influence percentage of the other factors were 
recalculated (Table 2). It was found that the model errors, aggregates accounting for $13.93 \%$ and therefore, to determine the regression equation it will be consider the parameters and the interactions among them.

Table 2. The percentage presentation of the cutting parameters influence exerted on the $\mathrm{R}_{\mathrm{a}}$ long [2]

\begin{tabular}{|c|c|c|c|c|c|c|}
\hline \multirow{2}{*}{ Source } & \multicolumn{2}{|c|}{ Freedom degrees } & \multicolumn{2}{c|}{ Square sum } & \multicolumn{2}{c|}{$\begin{array}{c}\text { Percentage } \\
\text { contribution }\end{array}$} \\
\cline { 2 - 7 } & $\begin{array}{c}\mathbf{R}_{\mathbf{a}} \\
\text { long }\end{array}$ & $\begin{array}{c}\mathbf{R}_{\mathbf{a}} \text { long } \\
\text { recalculated }\end{array}$ & $\mathbf{R}_{\mathbf{a}}$ long & $\begin{array}{c}\mathbf{R}_{\mathbf{a}} \text { long } \\
\text { recalculated }\end{array}$ & $\mathbf{R}_{\mathbf{a}}$ long & $\begin{array}{c}\mathbf{R}_{\mathbf{a}} \text { long } \\
\text { recalculated }\end{array}$ \\
\hline $\begin{array}{c}\text { Regression } \\
\text { model }\end{array}$ & 7 & 5 & 199.482 & 199.38 & $86.12 \%$ & $86.07 \%$ \\
\hline Cutting speed A & 1 & 1 & 194.322 & 194.322 & $83.89 \%$ & $83.89 \%$ \\
\hline Cutting depth B & 1 & - & 0.040 & - & $0.02 \%$ & - \\
\hline Feed per tooth C & 1 & 1 & 1.157 & 1.194 & $0.50 \%$ & $0.52 \%$ \\
\hline A x B & 1 & 1 & 3.093 & 0.569 & $1.34 \%$ & $0.25 \%$ \\
\hline A x C & 1 & 1 & 0.316 & 2.795 & $0.16 \%$ & $1.21 \%$ \\
\hline B x C & 1 & - & 0.366 & - & $0.14 \%$ & - \\
\hline A x B x C & 1 & 1 & 0.188 & 0.501 & $0.08 \%$ & $0.22 \%$ \\
\hline Error & 827 & 829 & 32.156 & 32.258 & $13.88 \%$ & $13.93 \%$ \\
\hline Fitting error & 143 & 145 & 18.735 & 18.837 & $8.09 \%$ & $8.13 \%$ \\
\hline Pure error & 684 & 684 & 13.421 & 13.421 & $5.79 \%$ & $5.79 \%$ \\
\hline Total & 834 & 834 & 231.638 & 231.638 & $100 \%$ & $100 \%$ \\
\hline
\end{tabular}

Thus, by MINITAB 17 using, and its predefined calculation procedure, the regression coefficients were determined and the regression equation related to $\mathrm{Ra}$ long, has the following form:

$$
\begin{aligned}
& R_{a} \operatorname{long}=0.000287 \cdot A-5.808 \cdot C+0.000196 \cdot A \cdot B+0.01345 \cdot A \cdot C \\
& -\quad 0.001582 \cdot A \cdot B \cdot C
\end{aligned}
$$

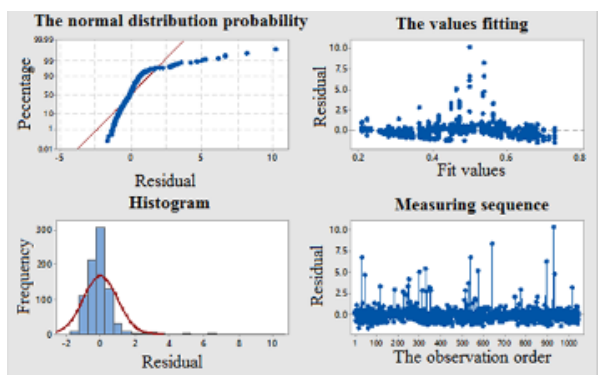

Fig. 1. The $\mathrm{R}_{\mathrm{a}}$ long equation residuals diagram.

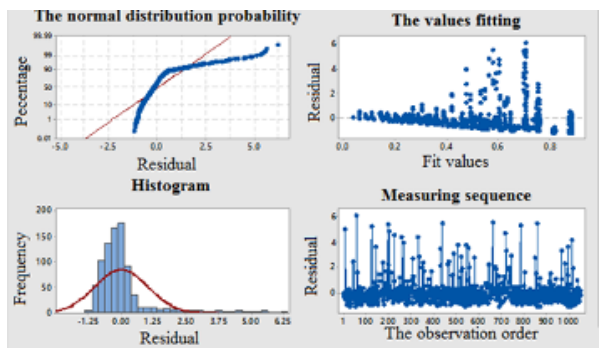

Fig. 2. The $\mathrm{R}_{\mathrm{a}}$ transv equation residuals diagram.

In Figure 1 the residual diagrams corresponding to the obtained regression equation are plotted. Analyzing the normal distribution it was found that the residuals does not approximate a straight line, and the distribution histogram of the residuals indicates some values that exceed a Gaussian distribution curve. This is due to the roughness values jumps recorded when the cutting speed is in the middle of the studied interval - 570-610 [m/min]. Regarding the values matching diagrams and the diagram with the measurements order, it was found that the residuals have a uniform distribution to the zero line but, in some cases, 
there are some big jumps from one value to another due to the recorded values at 570-610 $[\mathrm{m} / \mathrm{min}]$ cutting speeds.

\section{2 $R_{\mathrm{a}}$ transversal regression analysis}

Similar to the previous paragraph, Table 3 shows the $\mathrm{R}_{\mathrm{a}}$ transv situation. Also, the cutting speed is the parameter with the greatest influence on the surface roughness with $39.11 \%$. At the opposite side is the feed per tooth, whose influence on $\mathrm{R}_{\mathrm{a}}$ transv, is only $0.62 \%$.

Table 3. The percentage presentation of the cutting parameters influence exerted on the $R_{a}$ transv

\begin{tabular}{|c|c|c|c|}
\hline Source & Freedom degrees & Square sum & Percentage contribution \\
\hline Regression model & 7 & 229.728 & $46.24 \%$ \\
\hline Cutting speed A & 1 & 194.328 & $39.11 \%$ \\
\hline Cutting depth B & 1 & 27.813 & $5.60 \%$ \\
\hline Feed per tooth C & 1 & 3.078 & $0.62 \%$ \\
\hline A x B & 1 & 3.598 & $0.72 \%$ \\
\hline A x C & 1 & 0.007 & $0,001 \%$ \\
\hline B x C & 1 & 0.063 & $0,01 \%$ \\
\hline A x B x C & 1 & 0.842 & $0.17 \%$ \\
\hline Error & 846 & 267.089 & $53.76 \%$ \\
\hline Fitting error & 143 & 163.840 & $32.98 \%$ \\
\hline Pure error & 703 & 103.250 & $20.78 \%$ \\
\hline Total & 853 & 496.818 & $100 \%$ \\
\hline
\end{tabular}

The regression equation related Ra transv, has the following form (MINITAB 17):

$$
\begin{gathered}
R_{a} \text { transv }=-0.000416 \cdot A-0.027 \cdot B-12.23 \cdot C+0.000502 \cdot A \cdot B \\
+0.0182 \cdot \quad A \cdot C+4.67 \cdot B \cdot C-0.00767 \cdot A \cdot B \cdot C
\end{gathered}
$$

In Figure 2 the residual diagrams corresponding to the obtained regression equation are plotted and it is found that the residuals does not approximate a straight line, and the distribution histogram of the residuals indicates the some values that exceed a Gaussian distribution curve. The residuals have not a uniform distribution to the zero line because of the big jumps of the measured values at $570-610[\mathrm{~m} / \mathrm{min}]$ cutting speeds. Next for the each determinate regression equation, the variance analysis ANOVA will be used.

\section{The variance analysis ANOVA of the regression equation}

The ANOVA analysis terms were determined based on the MINITAB 17 calculation procedure, and they were centralized in Tables 4.

For $R_{a}$ long, given that the $F$ calculated value is higher than $F$ tubular's value $\left(F_{\text {calc }}>\right.$ $\mathrm{F}_{\text {tab }}$ ) and always greater than 1 , it can be considered that the relationship between the adjusting variables and the responses is statistically significant. Therefore, the mathematical model is acceptable and it permitted to describe the studied phenomenon evolution in the experimentally field, with a strong correlation between the studied factors, responses and the regression equation between the proposed and the experimental data obtained. But in the $\mathrm{R}_{\mathrm{a}}$ transv case, $\mathrm{F}_{\mathrm{cal}}>\mathrm{F}_{\mathrm{tab}}$ and it is not greater than 1, because the Ra transv data have not 
a normal distribution. Conducting the statistical analysis of the regression equations coefficients it was obtained the confidence significance of $85.92 \%$ for $\mathrm{R}_{\mathrm{a}}$ long and $45.53 \%$ for $\mathrm{R}_{\mathrm{a}}$ transv. This percentage has not a higher value due to the recorded data values distribution in the fields of $570-610[\mathrm{~m} / \mathrm{min}]$ of cutting speed.

Table 4. ANOVA from the $\mathrm{R}_{\mathrm{a}}$ regression equations

\begin{tabular}{|c|c|c|c|c|}
\hline \multirow{2}{*}{ Source } & \multicolumn{2}{|c|}{$\mathbf{F}_{\text {alc }}$} & \multicolumn{2}{c|}{$\mathbf{F}_{\text {tab }}$} \\
\cline { 2 - 5 } & $\mathrm{R}_{\mathrm{a}}$ long & $\mathrm{R}_{\mathrm{a}}$ transv & $\mathrm{R}_{\mathrm{a}}$ long & $\mathrm{R}_{\mathrm{a}}$ transv \\
\hline Regression model & 1025.09 & 103.954 & $\left(\mathrm{~F}_{0.05,5,834}\right) 2.225$ & $\left(\mathrm{~F}_{0.05,7,853}\right) 2.020$ \\
\hline A & 5.054 & 1.293 & $\left(\mathrm{~F}_{0.05,1,834}\right) 3.853$ & $\left(\mathrm{~F}_{0.05,1,853}\right) 3.853$ \\
\hline B & - & 0.039 & - & $\left(\mathrm{F}_{0.05,1,853}\right) 3.853$ \\
\hline C & 94.717 & 2.783 & $\left(\mathrm{~F}_{0.05,1,834}\right) 3.853$ & $\left(\mathrm{~F}_{0.05,1,853}\right) 3.853$ \\
\hline A x B & 22.429 & 3.903 & $\left(\mathrm{~F}_{0.05,1,834}\right) 3.853$ & $\left(\mathrm{~F}_{0.05,1,853}\right) 3.853$ \\
\hline A x C & 64.997 & 2.063 & $\left(\mathrm{~F}_{0.05,1,834}\right) 3.853$ & $\left(\mathrm{~F}_{0.05,1,853}\right) 3.853$ \\
\hline B x C & - & 2.864 & - & $\left(\mathrm{F}_{0.05,1,853}\right) 3.853$ \\
\hline A x B x C & 12.871 & 2.666 & $\left(\mathrm{~F}_{0.05,1,834}\right) 3.853$ & $\left(\mathrm{~F}_{0.05,1,853}\right) 3.853$ \\
\hline Fitting error & 6.628 & 7.799 & $\left(\mathrm{~F}_{0.05,145,834}\right) 1.222$ & $\left(\mathrm{~F}_{0.05,143,853}\right) 1.223$ \\
\hline
\end{tabular}

—Ra long experimental — Ra long calculated

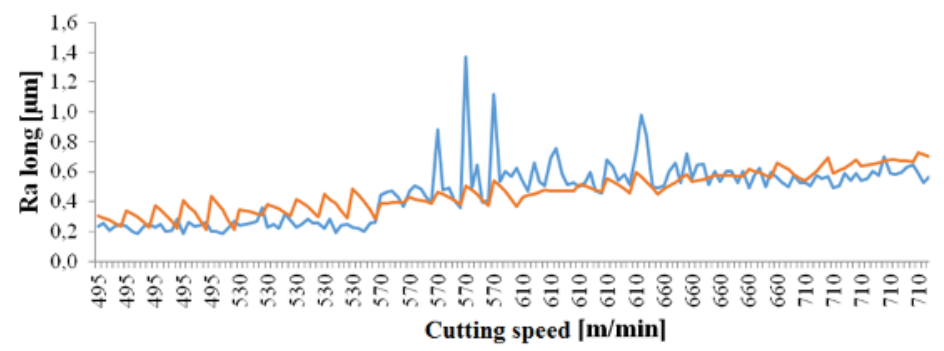

Fig. 3. The Ra long experimental measurements versus Ra long calculated measurements diagram

The last step that must be met to complete this research lies in results predicting at any point in the obtained experimentally range based on the regression model. Specifically, the arithmetic mean deviation of surface profile will be determined using the obtained regression equations. The graphical representations to compare the experimental measurements and the calculated values by using the equation, were made (fig. 3 and fig. 4). In both graphs, were introduced the $R_{a}$ long and $R_{a}$ transv evolution values, depending on the cutting speed, because this parameter has the greatest influence on the response. The problem of the higher errors values occurred in both cases, is caused by the cutting speeds of $570 \mathrm{~m} / \mathrm{min}$ and $610 \mathrm{~m} / \mathrm{min}$, where the arithmetic mean deviation of surface profile measured, recorded significant jumps distributions. 


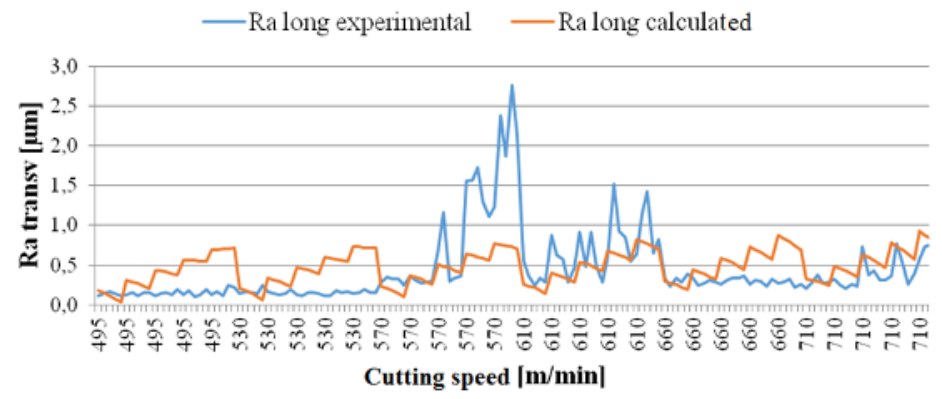

Fig. 4. The Ra transv experimental measurements versus Ra transv calculated measurements diagram.

\section{Conclusions}

After the performed regression analysis were identified the quantitative relationship between the cutting process parameters and the arithmetic mean deviation of surface profile. In both cases for $\mathrm{R}_{\mathrm{a}}$ long and for $\mathrm{R}_{\mathrm{a}}$ transv, cutting speed has the greatest influence on the arithmetic mean deviation of the machined surface profile. The obtained regression equations, approximates the studied system at any point in the chosen experimental range, with a grade of $85.91 \%$ in matching longitudinal Ra and $45.52 \%$ for transverse Ra.

The increases of the Ra values on $570 \mathrm{~m} / \mathrm{min}$ and $610 \mathrm{~m} / \mathrm{min}$ cutting speed, are caused by the vibrations occurred during the end milling process. The vibrations emergence, leads to a rough surface. These vibrations are the effect of the resonance phenomenon given by the contact between the tool and the workpiece and the materials used. The causes, the producing manner of and the vibration effect could be detailed studied in further research.

\section{References}

1. A.B. Bonţiu Pop, Proceedings of the International Conference of the Carpathian EuroRegion specialists in industrial systems-Ceursis 2014, (Technical University of Cluj Napoca, România, North University Center in Baia Mare, 2014)

2. A.B. Pop, M.A. Ţîţu, IOP Conf. Series: Materials Science and Engineering 161 (2016)

3. A.B. Bonţiu Pop, Applied Mechanics and Materials, Vols. 809-810, pp 123-128 (2015)

4. M. Țițu, C. Oprean, Al. Boroiu, Applied experimental research for increasing the quality of products and services (in Romanian) (AGIR Publishing House, Bucharest, 2011)

5. A. Kannan, K. Esakkiraja, M. Nataraj, Journal of Mechanical and Civil Engineering 9, 4, 59-64 (2013)

6. Z.A. Shekh, T.A. Khan, International Journal of Scientific Engineering and Technology 2, 7, 705-709 (2013)

7. D. Vakondios, Kyratsis, P., Yaldiz, A. Measurement, 45, 6, 1480-1488 (2012)

8. A.B. Bonțiu Pop, Aluminum alloys surface quality by cylindrical-frontal milling (in Romanian), (PhD Dissertation, Technical University of Cluj Napoca, România, North University Center in Baia Mare, 2015) 